\title{
Fortalecimiento competencia interpretativa para potencializar procesos de aprendizaje en lenguaje y matemáticas
}

Yaned Montañez-Gómez * Claudia Rubio-Torres **

Artículo de investigación

Fecha de Recepción: 13 diciembre 2017.

Fecha de Aprobación: 1 mayo 2018.

\section{Resumen}

Para contribuir con los retos de la educación del siglo XXI, sumado a los cambios en el conocimiento y a la manera de enseñar y aprender de las nuevas generaciones vinculadas a un mundo en continuo crecimiento y amplia accesibilidad a la comunicación e información que incide a nivel global en la interpretación de diferentes clases de texto procedentes de cualquier lugar del planeta y de todo tipo de culturas, religiones e ideologías, es necesario que la escuela capacite educandos en lectura interpretativa de textos para discernirla, por tal razón, nuestra investigación estableció como objetivo implementar una estrategia didáctica que permita fortalecer las habilidades de la competencia interpretativa de un texto para potencializar los procesos de aprendizaje de los estudiantes, que modifiquen sus proyectos de vida y mejoren el rendimiento académico de la institución educativa. Es una investigación acción de corte cualitativo, partió de autorreflexiones de las prácticas educativas con los estudiantes del grado 9-1, para formar estudiantes competentes con aprendizajes significativos. Para el

\section{* Institución Educativa Tomás Vásquez Rodríguez - Boyacá - Colombia \\ claudesruto@gmail.com \\ ** Institución Educativa Tomás Vásquez Rodríguez - Boyacá - Colombia mavaya5218@hotmail.com}

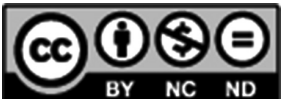


análisis de resultados se utilizó un método mixto, se establecieron dos categorías de estudio, encontrando que la estrategia didáctica implementada fortaleció la competencia interpretativa de los textos para asimilar el conocimiento.
Palabras clave: Habilidades interpretativas, tareas docentes, textos multimodales, procesos de aprendizaje, aprendizaje significativo. 


\section{Planteamiento}

La investigación en educación y pedagogía tiene dos impactos centrales, primero, se produce conocimiento sobre la educación, al estudiar problemas de educabilidad del ser humano o los relacionados con la enseñabilidad de cada una de las ciencias y de las disciplinas, en segundo lugar busca la formación de docentes como investigadores para formar a los estudiantes en un ambiente de investigación y desarrollo social, por tanto es fundamental, que el docente los prepare para el futuro en la enseñanza de la lectura y de paso en la escritura, para volverlos procesos naturales y reducir la aversión frente a la cualificación de las habilidades interpretativas; esto, llevó a plantear el problema con respecto a la dificultad en la interpretación de un texto al abordar una nueva información que obstaculiza el proceso de aprendizaje y la aplicación de conceptos y algoritmos en la resolución de problemas propuestos, la cual se evidencia cuando los estudiantes al leer un texto lo hacen de manera mecánica leyendo por leer, sin buscar significados desconocidos para tener mayor claridad y comprensión del mismo, así como, determinar rasgos y nexos principales y secundarios que resalten las ideas principales para relacionarlas entre sí sintetizándolas en una idea personal $y$ general que constituya un nuevo aprendizaje.

Para el desarrollo del presente artículo se tomaron como antecedentes las investigaciones y reflexiones de Daniel
Casanny, una de ellas, "10 claves para enseñar a interpretar" que significa "valorar críticamente un texto, si comprender es construir el significado del texto (visto como mensaje comunicativo), interpretar requiere tomarconciencia del usoy del valor deéste (visto como artefacto social y político)", teniendo en cuenta que el interés de la propuesta de investigación se enfoca en el fortalecimiento de las habilidades de pensamiento: observar, analizar, comparar, determinar lo esencial, abstraer, sintetizar, conceptualizar, caracterizar, describir, identificar, relacionar e interpretar (Sánchez y Vanegas, 1997) de la competencia interpretativa que busca encontrar las ideas principales de textos como situaciones problema, proposiciones, gráficas, mapas y esquemas para reconstruir un pensamiento interpretativo del entorno cotidiano. Así como, en las investigaciones de Alexander Ortiz Ocaña (2015) que fundamenta "un modelo didáctico para el desarrollo del pensamiento, las habilidades y las competencias desde el aula de clase, mediante la aplicación de tareas docentes que constituye un núcleo del trabajo independiente de los estudiantes guiadas por el docente"; trabajos que aportan amplios conocimientos para el desarrollo de esta propuesta cuya finalidad principal es encontrar una estrategia didáctica que permita potencializar los procesos de aprendizaje relacionados con la recepción y la asimilación de los saberes transmitidos a los estudiantes en cada disciplina, especialmente Lenguaje y Matemáticas y de la vida diaria en general, que se evidencian mediante las
La investigación en educación y pedagogía tiene dos impactos centrales, primero, se produce conocimiento sobre la educación, al estudiar problemas de educabilidad del ser humano o los relacionados con la enseñabilidad de cada una de las ciencias y de las disciplinas 
La propuesta de investigación descrita en este artículo está enmarcada dentro de un proceso de investigación acción (Elliot,2000) de corte cualitativo capacidades o conductas del estudiante que dependen del tiempo y la constancia que se dedique para obtenerlos.

Retomando lo anterior, se quiere contribuir con la línea de investigación del programa de la Maestría en Educación modalidad profundización dentro del eje temático didáctica de los saberes escolares con este artículo, que toma como punto de partida el preguntarse sobre ¿Cuál estrategia didáctica que fortalece las habilidades de la competencia interpretativa de un texto para potencializar los procesos de aprendizaje de los estudiantes del grado 9-1 en las áreas de lenguaje y matemáticas?, con el propósito de formular un proyecto de aula que mejore el aprendizaje de los educandos, despertando la motivación por aprender, manteniendo la disposición hacia el aprendizaje para optimizar la calidad de vida, por consiguiente, los resultados académicos y las pruebas externas de los estudiantes $\mathrm{y}$ de la institución. Este interrogante surgió del estudio concienzudo de las experiencias, reflexiones, visiones de los actores involucrados en el quehacer escolar como son los docentes, estudiantes y padres de familia del grado 9-1 conformado por 26 estudiantes, el cual, se tomó como grupo representativo para realizar el diagnóstico de la investigación, de igual forma, el análisis de documentos como el Plan Educativo Institucional (PEI), el modelo pedagógico, los resultados académicos y los resultados obtenidos en las pruebas SABER (ISCE).
La propuesta de investigación descrita en este artículo está enmarcada dentro de un proceso de investigación acción (Elliot, 2000) de corte cualitativo, el cual, parte de una autorreflexión de la práctica educativa y supone encontrar una posible solución a la cuestión establecida, que es susceptible de mejoramiento con la implementación de una estrategia didáctica que fortalezca las habilidades de la competencia interpretativa de un texto para potencializar los procesos de aprendizaje en las asignaturas de Lenguaje y Matemáticas que permita asimilar los conceptos y ponerlos en práctica para la solución de problemas de la vida cotidiana.

En las siguientes secciones van a encontrar el marco conceptual, la metodología, el contexto de estudio, el desarrollo de las fases investigación acción, los análisis y resultados de cada las categorías de estudio, conclusiones y referencias bibliográficas.

\section{Fundamentación Teórica}

De acuerdo con los Artículos 20 y 23 la Ley General de la educación que dispone dentro de las áreas obligatorias y fundamentales del conocimiento y de la formación a matemáticas y humanidades, con los objetivos específicos: Desarrollar habilidades comunicativas básicas para leer, comprender textos y expresar correctamente mensajes complejos, orales y escritos en lengua castellana y desarrollar conocimientos matemáticos necesarios para manejar y utilizar operaciones de cálculo y 
procedimientos lógicos en diferentes situaciones, así como la capacidad para solucionar problemas, que impliquen estos conocimientos y su utilización en la interpretación de la ciencia, de la tecnología y los de la vida cotidiana.

Analizando la dificultad que se presenta con el logro de éstos objetivos en la comunidad estudiantil se planteó un proceso de investigación acción para conocer las causas que la generan, las cuales, se manifiestan en la aprensión, la desmotivación, la dificultad para resolver situaciones problema y el bajo rendimiento académico obtenido en estas áreas, esto, condujo a plantear el problema: La dificultad en la interpretación de un texto obstaculiza el proceso de aprendizaje y la aplicación de conceptos para la resolución de problemas propuestos, el cual, se analizó a través de un diagnóstico utilizando técnicas e instrumentos para recolección de la información, tales como, la observación directa de las prácticas de aula en éstas áreas, diseñando y aplicando entrevistas y encuestas para conocer las visiones de cada uno de los actores que intervienen en el proceso enseñanza aprendizaje, analizando documentos como resultados académicos, resultados de pruebas SABER (ISCE), modelo pedagógico de la institución y referentes bibliográficos; con el respectivo resultado, se evidenció la dificultad en la interpretación de textos al momento de abordar la lectura de conceptos, definiciones, imágenes, gráficas, símbolos, entre otros tipos de texto que dificulta la comprensión del tema, por tanto, obstruye el proceso de aprendizaje y la aplicación de la información en la resolución de situaciones problema, esto motivó a las docentes a comenzar un trabajo de investigación a partir de la construcción de la pregunta.

Este cuestionamiento, llevó a consultar varios referentes teóricos que indicaran los caminos por los cuales poder avanzar, dentro de éstos se retomaron, las teorías del aprendizaje activo de la corriente constructivista (Ernst von Glasersfeld,1970); desde las concepciones: filosófica (Piaget, 1970), la consideró como una estrategia de enseñanza-aprendizaje, es un aprendizaje que solo puede adquirirse a través de la implicación, motivación, aplicación y trabajo constante del estudiante y una enseñanza donde el profesor es quien guía el proceso de búsqueda, orienta el desarrollo del conocimiento, facilita y posibilita diferentes actividades con el propósito de que los estudiantes se impliquen, trabajen ciertos aprendizajes y aclaren aquellos conocimientos que les puede suponer grandes dificultades; psicológica (Ausubel, 1976), supone un aprendizaje significativo, puesto que produce un cambio en las estructuras mentales del estudiante, puede lograrse a través del análisis, comprensión, elaboración, trabajo, asimilación y tratamiento de la información propuesta en forma activa; social (Vygotsky, 1934), el aprendizaje no se considera como una actividad individual, sino más bien social, aprende eficazmente cuando lo hace en forma cooperativa, sin descartar el trabajo individual para lograr sus 
En la metodología ABP, no se trata de la mera resolución del problema (resultado), sino también la construcción del mismo (proceso). propias reflexiones y socializarlas con los demás, esto genera un aprendizaje asertivo que se manifiesta cuando el estudiante expresa sentimientos, actitudes, deseos, opiniones o derechos de un modo adecuado a la situación, respetando a los demás, generalmente resuelve problemas inmediatos de la situación, mientras minimiza la probabilidad de futuros problemas (Caballo, 2005).

A partir de estas teorías, se infiere el trabajo activo, la disposición del estudiante y la socialización del mismo para obtener aprendizaje significativo, es decir, hace reestructuraciones activas de las percepciones, ideas, conceptos y esquemas que ya posee en su estructura cognitiva como saberes previos, realiza juicios de pertinencia, determina discrepancias, contradicciones, similitudes y desarrolla procesos de análisis y síntesis con la información, reorganiza sus conocimientos bajo principios explicativos más inclusivos y amplios (Díaz, 1999, p. 21), que implica una enseñanza adecuada a las necesidades del estudiante, a las características de sus capacidades y de sus aprendizajes previos, que mantenga el interés, la motivación y la guía del proceso de búsqueda del conocimiento hasta lograr el desarrollo de las habilidades que lo vuelvan competitivo en el proceso cognitivo, lógico y práctico que le permitan resolver problemas de su entorno, ya que la vida misma lo obliga a hacerlo, sin tener claridad de la vía de solución, sino, que depende de los conocimientos que tenga, del interés y la lógica para realizar los procedimientos requeridos y encontrar la solución (Pérez, L. \& Rizo, C., 1996).
Por lo anterior, la estrategia didáctica buscada deberá identificar y plantear el análisis del proceso de enseñanzaaprendizaje; en el cual el docente y el estudiante puedan constatar hasta donde han sido capaces de ser eficientes: los primeros en la orientación y dirección y los segundos en la adquisición de los niveles de independencia necesarios y suficientes para aprender, autoevaluarse y participar activamente en el proceso de la coevaluación, donde se definen estilos, estrategias, métodos y formas de orientar y aprender, esto se logra a través de la implementación de la estrategia didáctica "tarea docente" (Álvarez de Zayas, 1994), que constituye el núcleo del trabajo independiente de los estudiantes, en la cual se plantea un objetivo que debe lograrse a lo largo de ejecución mediante solución de ejercicios y problemas para entrenar habilidades, es decir, mediante la clase práctica, que permite reforzar los conceptos adquiridos y los nuevos por aprender.

La tarea docente es considerada la célula del proceso, en la cual existe un contenido a asimilar y una habilidad a desarrollar, ya que al reunir el eslabón o conexión de ideas elaboradas con los nuevos conocimientos y los saberes previos, contiene una contradicción fundamental del proceso que se da en el objetivo declarado por el profesor y la necesidad de vencerlo por el estudiante; contiene los componentes y regularidades esenciales de dicho objetivo como los recursos que puede utilizar o elementos dados por la situación y una serie de operaciones que pueden aplicarse a los recursos 
disponibles para alcanzar el producto; es decir, una tarea provoca la realización de un proceso o procesos dirigidos, utilizando recursos y produciendo resultados. De igual forma, resulta importante señalar que varias tareas docentes (sistema de tareas) pueden estar dirigidas a un mismo objetivo pero aumentando su complejidad. "El objetivo se expresa en término de habilidades, la aspiración se concreta en la acción y el resultado obtenido es la competencia adquirida por el estudiante”. (Ortiz, 2015, p.99).

\section{Etapas de la tarea docente:}

Etapa de orientación. La Base Orientadora para la acción que debe seguir para lograr el objetivo.

Etapa de ejecución. representación mental de lo que va a hacer.

$\checkmark$ Etapa de organización de la Información. Disponer de un período suficiente de tiempo para dar solución a la tarea.

Etapa de evaluación. La medida del cumplimiento del objetivo determinado.

Es necesario, mediante esta estrategia didáctica incentivar la lectura interpretativa en los estudiantes fortaleciendo habilidades para optimizar el aprendizaje significativo de los contenidos estudiados, por tanto, la estrategia didáctica que responde a estos intereses es "tareas docentes", porque, con el planeamiento organizado y la ejecución desarrolla la competencia lectura con la construcción de significados a partir de la interacción entre el lector y el texto, ya que, el núcleo de este proceso es la elaboración de inferencias que va más allá del sentido literal y explícito que presenta el texto.

Cuando los estudiantes se enfrentan a la tarea de comprender un texto escrito, gráfico, virtual, entre otros, deben saber qué estrategias y procedimientos utilizar para poder inferir la información implícita del texto. Enseñar a hacer inferencias, basadas en conocimientos previos y lingüísticos, acerca del significado de una palabra extraña, propiedades de objetos, características o rasgos de los personajes o conceptos, el modo de analizar acciones y procedimientos, causas y efectos de sucesos, entre otras, es el modo de proceder más idóneo dentro del aula para desarrollar la habilidad interpretativa y convertirlos en lectores autónomos capaces de superar cualquier obstáculo que dificulta su proceso de comprensión lectora (Cassany, 2016).

De acuerdo con este objetivo, se requiere de un trabajo arduo por parte de las docentes para lograr una enseñanza de calidad (Solé \& Coll, 1990, p.163) y de los estudiantes como participantes activos en el proceso de adquisición del conocimiento, fundamentada por el aprendizaje activo del constructivismo que se centra en el estudiante, para incentivar participación y reflexión continua a través de actividades que promuevan el diálogo, la colaboración, el desarrollo y la construcción de conocimientos, así como habilidades y actitudes, con la finalidad de lograr
"El objetivo se expresa en término de habilidades, la aspiración se concreta en la acción y el resultado obtenido es la competencia adquirida por el estudiante" 
procesos de aprendizaje que le permitan establecer relaciones apropiadas de ideas en función de la solución de problemas y la toma de decisiones con originalidad, creatividad, capacidad crítica y reflexiva.

Con lo anterior, se puede establecer que la construcción de los procesos de aprendizaje, es decir, de la red de esquemas de conocimientos definidos por las representaciones que una persona posee en un momento dado de su existencia sobre algún objeto de conocimiento, que a lo largo de la vida, se revisan, se modifican, se vuelven más complejos y adaptados a la realidad, llegan a producir cambios en las capacidades o conductas del estudiante que dependen de las características singulares de ellos, de las experiencias vividas, de la forma en que aprenden y del ritmo de aprendizaje que varía de acuerdo a sus capacidades, motivaciones e intereses que cada uno tiene desde su nacimiento, es decir, la manera en que se producen aprendizajes son el resultado de procesos que son singulares o personales, del tiempo y la constancia que se dedique para obtenerlos (Zabala, 2000), posibilitando inferir, que el cambio se logra a través del aprendizaje de la información, de los estímulos del ambiente que recibe el estudiante a través de los receptores, que son estructuras en el sistema nervioso central que llevan la información al cerebro, el cual, está compuesto por dos hemisferios el izquierdo y el derecho, el hemisferio izquierdo rige la parte racional del ser humano, es el origen de las funciones lógicas, analíticas y verbales, ejerce mayor control sobre la destreza manual, la lectura y el lenguaje y el hemisferio derecho rige la parte emocional, actúa con la comunicación no verbal, dotado de sensibilidad y capacidad espacial, involucra la creatividad y los aspectos excepcionales del talento humano y da la respuesta correspondiente al estímulo brindado.

Por tanto, la mayoría de las actividades que se realizan requieren de la intervención conjunta de las funciones localizadas en los dos hemisferios. Por ejemplo, para realizar procesos de aprendizaje de matemática y de lenguaje, el estudiante debe tener expectativa o motivación para aprender, esto lo debe ofrecer la escuela, el aula, la evaluación, la disciplina y las relaciones entre maestros, alumnos y padres de familia, para brindar ambientes adecuados e idóneos que generen aprendizaje; esta información es importante para las instituciones educativas, por cuanto, demuestra científicamente la identificación del centro de los procesos cognitivos y afectivos del ser humano que originan la conducta de los estudiantes (Ortiz, 2015).

Por esta razón, la importancia para el desarrollo de esta propuesta es saber ¿cómo se genera el aprendizaje en las áreas de lenguaje y matemáticas?, que son las áreas focalizadas para fortalecer los procesos de aprendizaje. Entre las teorías científicas que dan razón sobre el funcionamiento del lenguaje humano se halla la gramática generativa, actualmente llamada, biolingüística que permite evidenciar el hallazgo de una estructura mental inherente que posibilita la producción 
y comprensión de cualquier enunciado facilitando una estrecha relación entre el aprendizaje y la práctica, este avance del lenguaje permite expresar infinidad de ideas, informaciones y emisiones, que se van asimilando en el cerebro de tal manera que cumpla un proceso en constante evolución, que puede ir mejorando cada día con la práctica social, de acuerdo con las pautas y normas que se van planteando en las versiones oral y escrita. (Chomsky, 1988). La competencia lingüística más la competencia pragmática es igual a la competencia comunicativa, y uno de los ejes referidos al proceso de interpretación suponen la existencia de sujetos en condiciones de comprender, interpretar, analizar y producir tipos de textos según sus necesidades de acción y comunicación (Cassany, 2016).

Por otro lado, existen teorías que han intentado explicar el proceso de aprendizaje en matemáticas y coinciden en que el objetivo de la enseñanza de las matemáticas no es solo aprender las tradicionales reglas aritméticas, unidades de medida $y$ nociones geométricas y estadísticas, sino que su principal finalidad es la resolución de problemas y la aplicación de conceptos y habilidades matemáticas para desenvolverse en la vida cotidiana, como lo afirma Zoltan Dienes en su teoría sobre las seis etapas de enseñanza y aprendizaje: la adaptación, la estructuración, la abstracción, la representación gráfica o esquemática, la formalización y la demostración, que constituyen en el educando el desarrollo del pensamiento y las competencias a través del juego.
(Dienes, 1970). Por otra parte, se deben distinguir dos tipologías de objetos en el ámbito de la creación de la competencia matemática (aprendizaje matemático): el objeto matemático en sí mismo y el objeto lingüístico que lo expresa (D’Amore, 2013).

\section{Metodología}

La propuesta de investigación tiene un enfoque cualitativo porque estudia la realidad del contexto escolar de la institución educativa en forma inductiva y dinámica (Blasco \& Pérez, 2007), bajo un principio holístico en donde intervinieron las docentes vinculadas a la investigación junto al grupo de estudio, con una perspectiva de investigación acción, en el que se hizo un análisis auto reflexivo, con la finalidad de mejorar las prácticas educativas y el proceso de enseñanza aprendizaje de los docentes $\mathrm{y}$ estudiantes para fortalecer el desempeño académico de la institución educativa (Elliot, 2000).

Para registrar los datos y resultados de lo que sucedió en la ejecución de cada una de las fases se realizaron registros utilizando guiones, relacionando los hechos ocurridos durante la aplicación de los instrumentos de recolección de la información transcritos en forma narrativa en los diarios de campo, interpretando "lo que ocurrió" desde el punto de vista de quienes actúan e interactúan en la situación problema, es decir, los docentes que dirigen las clases en el grado 9-1, los estudiantes, los pares y los padres de familia, estas opiniones se interpretaron como
La competencia lingüística más la competencia pragmática es igual a la competencia comunicativa, y uno de los ejes referidos al proceso de interpretación suponen la existencia de sujetos en condiciones de comprender 
acciones y transacciones humanas y no como procesos. Se tomaron los datos a través de diálogos libres y en confianza, de tal forma que la información que se recibió fue real porque se confrontaron resultados para conocer la verdad y sobre ella poder actuar. Se utilizaron: la técnica de la observación mediante instrumentos como: diarios de campo, talleres, cuestionarios, encuestas, entrevistas, así como la técnica análisis de documentos tales como: el P.E.I, el modelo pedagógico, los resultados pruebas SABER (ISCE), los resultados académicos y fuentes bibliográficas.

\section{Contexto de estudio}

La Institución Educativa Técnica Tomás Vásquez Rodríguez del municipio de Paipa aprobada mediante el Acuerdo 006 de 1992, es de carácter público vinculada al Ministerio de Educación Nacional, cuenta con una población de 1200 estudiantes dentro de la educación básica primaria, secundaria y media, la mayoría provenientes de hogares de estratos 1 y 2 con notoria descomposición familiar, las actividades socioeconómicas a las que se dedican son la agricultura, la construcción, amas de casa, conductores, trabajos informales, entre otros, la gran parte de padres de familia cuentan con baja formación académica; para el desarrollo de la investigación se tomó como grupo de estudio 26 estudiantes, entre las edades de 14 a 16 años, que en el momento en que se realizó el diagnóstico cursaban el grado 8-1 y para la implementación de la propuesta realizaban el grado 9-1, situados en la etapa operacional formal según Piaget (1970).

\section{Fases del desarrollo de la investigación acción:}

La propuesta de investigación se desarrollará a través de las fases planteadas en la investigación acción:

Fase 1: Identificación del problema, diagnóstico y construcción de la pregunta de investigación.

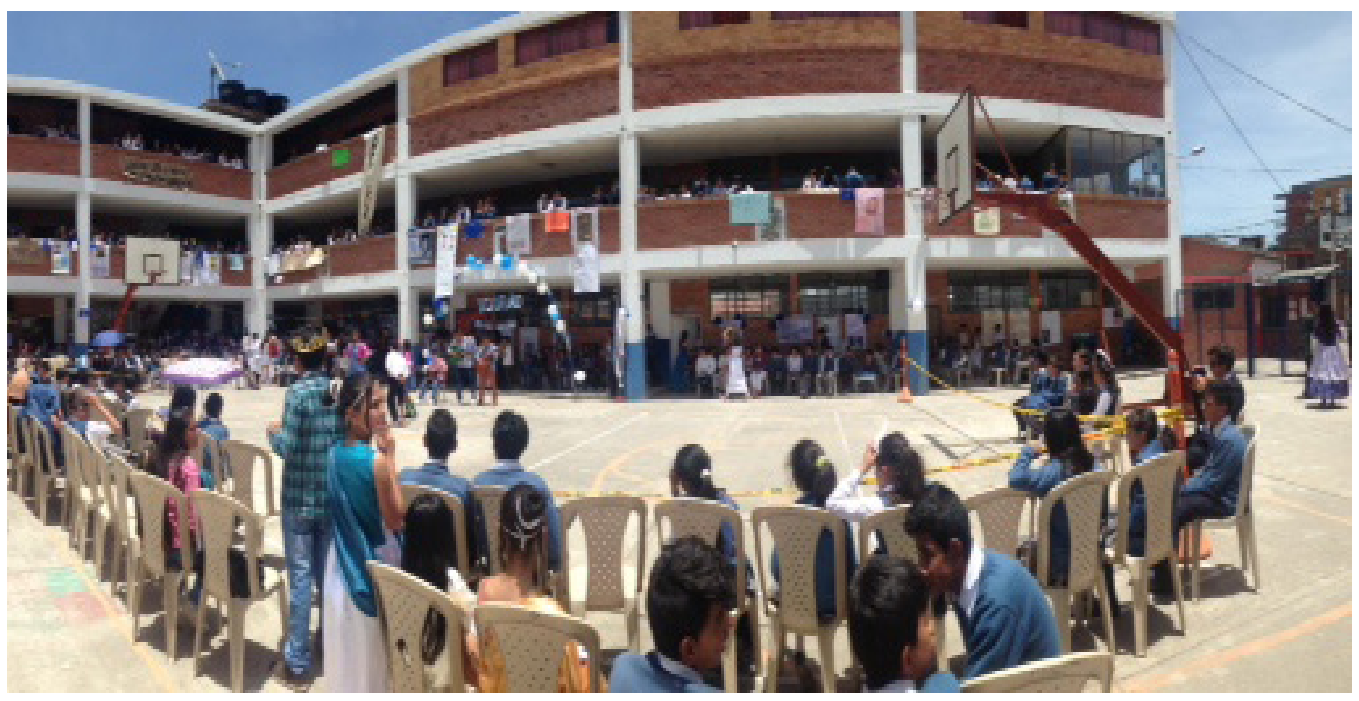


Fase 2: Planificación, implementación, evaluación.

Fase 3: Análisis de resultados, reflexión, evaluación

\section{Procedimiento}

Fase 1: Identificación del problema, diagnóstico y construcción de la pregunta de investigación.

En esta fase se identificó por observación directa en las clases de lenguaje y matemáticas el problema que afectaba los procesos de aprendizaje y el rendimiento académico de los estudiantes del grado 9-1, se realizaron algunas tomas fotográficas y videos de los procesos de enseñanza y aprendizaje con el grado, para lo cual, se tramitaron las autorizaciones de los padres de familia a los que se les dio a conocer la propuesta de investigación, de igual forma, que se hizo y tramitó el permiso ante el señor rector, para utilizar el nombre del colegio en la ponencia realizada y los documentos escritos presentados; se ratificó el planteamiento del problema aplicando tres encuestas estructuradas construidas por las docentes investigadoras tomando como referentes ítems de la comprensión lectora, la primera con 10 ítems para docentes de la institución que orientan clases en grado 9-1 y conversaciones informales; la segunda encuesta con 7 ítems para padres de familia del grado, porque las investigadoras quisimos conocer la opinión y contribución de estos actores en la formación intelectual de los estudiantes y la tercera encuesta con 10 ítems para estudiantes, las cuales se sometieron a validación con docentes de diferentes áreas y con estudiantes de otros grados, para recibir sugerencias sobre la formulación y comprensión de las preguntas, así como, una entrevista informal con una pregunta aplicada a los estudiantes y una entrevista semiestructurada compuesta por tres preguntas, se aplicaron a diez profesores, 26 padres y 26 estudiantes del grado. Además, se elaboraron tres talleres diagnósticos de matemáticas y lenguaje para los estudiantes del grado 9-1: taller 1 construcción de tangram de siete fichas, taller 2 teorema de Pitágoras (Modelo de Van Hiele, 1957) y taller 3 acertijos matemáticos para conocer cuál era el nivel de la competencia interpretativa en la lectura de textos. Se analizaron documentos como boletines de resultados académicos por periodos, los resultados de las pruebas SABER (ISCE) de noveno de los años 2015 y 2016, el P.E.I., planes de estudio y se consultaron varias fuentes bibliográficas.

Los resultados obtenidos con la aplicación de encuestas y entrevistas a los estudiantes, los docentes y padres de familia se tabularon, se sistematizaron y analizaron, utilizando un método mixto cualitativo y cuantitativo y se construyeron tablas con la escala Likert, encontrando lo siguiente:

En los estudiantes:

La encuesta aplicada a los estudiantes permitió concluir, que en las prácticas donde ellos realizan interpretación textual, el 27\% manifiesta hacer inferencia textual para lograr claridad y entendimiento de lo leído, el 
35\% afirma reconocer el propósito estructural del texto y el 33\% dicen interpretar textos multimodales.

En los docentes:

El $90 \%$ concientiza a los estudiantes de la importancia de leer y analizan textos durante las clases, el $80 \%$ manifiesta desarrollar la competencia interpretativa en el aula, el $80 \%$ plantea utilizar estrategias didácticas para propiciar la interpretación textual durante el desarrollo de las clases, el $80 \%$ la tiene en cuenta la comprensión de lectura en la planeación de clases.

En los padres de familia:

El 8\% de los padres incentiva siempre la lectura de los hijos en casa, a pesar de que el 80\% de ellos son conscientes que de ella depende el éxito en los resultados académicos, el 24\% siempre brindan espacios en familia para leer e interpretar textos generando preguntas de comprensión, el 40\% incentiva a los hijos para leer textos informativos con el fin de hacer las tareas escolares, con un 68\% motiva a los hijos a buscar las palabras desconocidas en el diccionario, el 32\% de los padres siempre le colaboran al hijo para interpretar conceptos de matemáticas y aplicarlos en la solución de problemas.

Con la aplicación de los talleres:

Los resultados obtenidos con la aplicación de los talleres diseñados fueron: Empatía por la lectura en un $10 \%$ de los estudiantes, encontró las ideas principales, infirió el tema central del texto y manejó adecuadamente el vocabulario; un $30 \%$ sintetizó textos escritos con expresiones matemáticas, realizó algoritmos para solución de ejercicios y problemas aplicando conceptos; un 10\% presentó independencia en el trabajo, suficiente manejo y dominio de conocimientos previos.

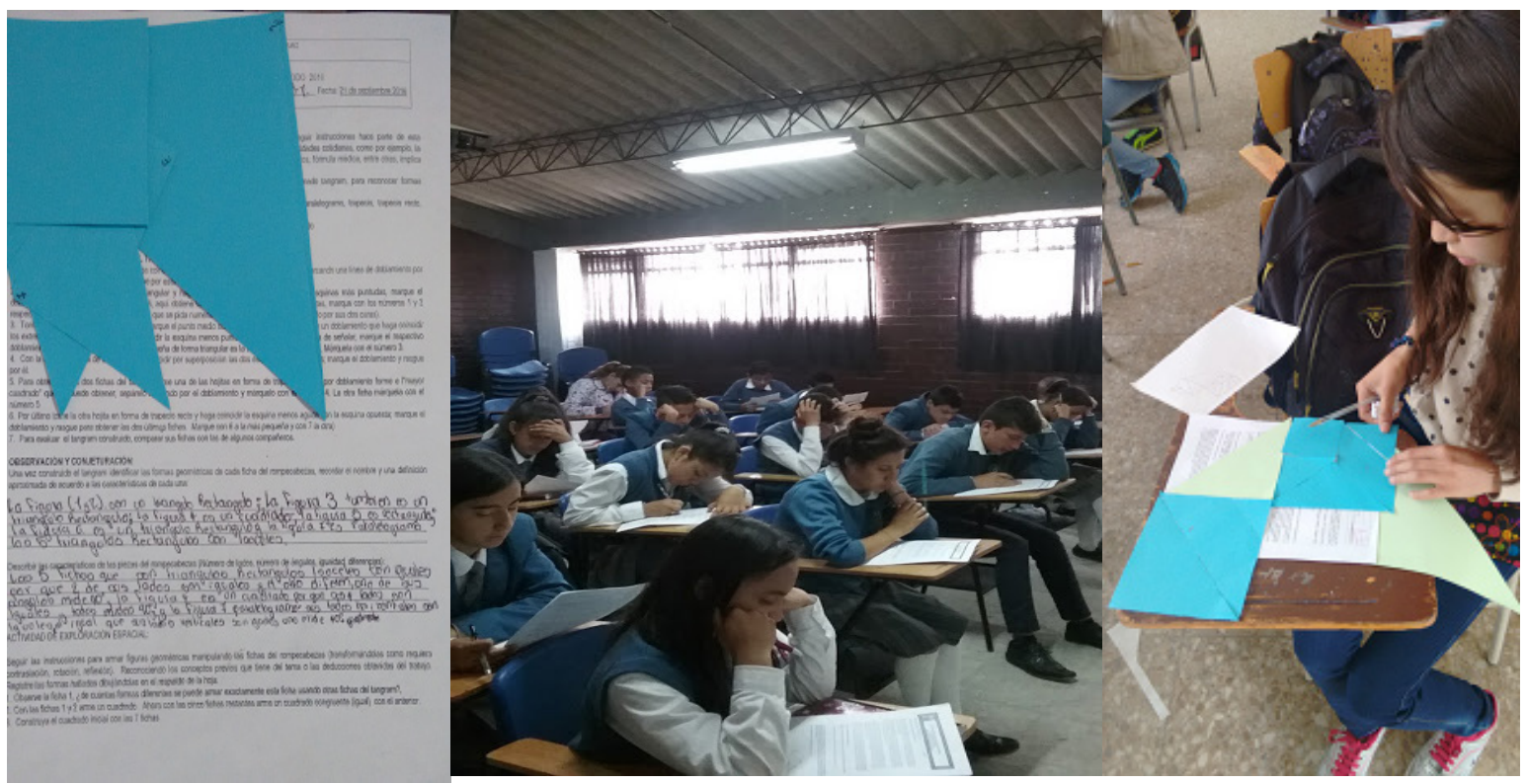


Entrevista realizada de una pregunta: Las respuestas de los estudiantes a la pregunta ¿Qué obstáculos se presentan en el aprendizaje de las diferentes áreas?, un $80 \%$ de ellos coincidieron con las siguientes respuestas: Dificultad para aprender, recordar y aplicar fórmulas, falta de concentración para escuchar las explicaciones del docente, falta de organización y hábitos de estudio, inaplicabilidad de la teoría estudiada en ejercicios de aplicación, poca claridad y creatividad en el desarrollo de las clases de los docentes, rechazo hacia la lectura y mucho más cuando no es interesante, falta de responsabilidad con las actividades asignadas, poca comunicación con los docentes, falta apoyo por parte de los padres de familia, mala utilización del tiempo libre.

Realizando la triangulación de la información obtenida en cada uno de los estamentos involucrados en la fase diagnóstica con la aplicación de los instrumentos aplicados a los estudiantes y padres de familia reconocen un bajo manejo de interpretación en el contexto educativo y familiar, mientras que los docentes afirman que sí la trabajan y buscan estrategias didácticas para fortalecerla.

Fase 2: Planificación, implementación, evaluación.

A partir de la documentación teórica, leyendo diferentes autores, que respondieran o insinuaran una posible solución a la inquietud del grupo de investigación sobre ¿Cuál estrategia didáctica fortalece las habilidades de la competencia interpretativa de un texto para potencializar los procesos de aprendizaje de los estudiantes del grado 9-1 en las áreas de lenguaje y matemáticas de la Institución Educativa Tomás Vásquez Rodríguez del municipio de Paipa?. Se encontraron dos autores que aportaron ideas para encaminar el trabajo de investigación, ellos fueron: El doctor en Ciencias Pedagógicas Alexander Ortiz Ocaña (Cuba, 2015) y el doctor en Enseñanza de Lenguas y Literatura Daniel Cassany (España, 1999).

Una vez encontrados los resultados del diagnóstico mediante los instrumentos aplicados y donde se evidenciaron dificultades en los estudiantes con respecto a las habilidades de la competencia interpretativa, las docentes investigadoras procedieron a planificar, diseñar y aplicar cinco tareas docentes en la asignatura de lenguaje y cinco en la asignatura de matemáticas, aplicando la interdisciplinariedad, estas tareas docentes se construyeron teniendo en cuenta los componentes que las conforman, las competencias curriculares con los conocimientos y habilidades y las temáticas de acuerdo a los estándares, los lineamientos curriculares y los derechos básicos de aprendizaje emanados del M.EN, que fueron validadas por los docentes Magíster de Matemáticas y Educación de la institución.

La estructura básica partió de una introducción sobre la interpretación, un objetivo de la propuesta, el tema, el objetivo de la tarea, los saberes previos, la modalidad del trabajo, la situación problema, los recursos y actividades 
enfocadas a fortalecer las habilidades de la competencia interpretativa como: observar, analizar, comparar, determinar lo esencial, abstraer, sintetizar, conceptualizar, caracterizar, identificar, describir, relacionar e interpretar (Álvarez de Zayas, 1994).

Las tarea docente, lleva implícito el contenido que debe dominar; el método, es el modo en que cada estudiante lleva a cabo la acción para apropiarse de ése contenido; los medios, que no son más que los materiales que utiliza para la solución de la tarea, con ayuda de los cuales se logra el objetivo y es a través de la evaluación que se comprueba si el estudiante ejecutó correctamente la tarea.

La planeación, elaboración y aplicación de las tareas docentes, pasó por un proceso de replanteamiento teniendo en cuenta la fundamentación teórica de diferentes autores V. V. Davidov; M. R Concepción; A. Medina Rivilla; C. M. Álvarez de Zayas.

Primeras tareas docentes elaboradas y aplicadas en lenguaje y matemáticas:

En el proceso del desarrollo de la investigación se elaboraron las tareas docentes teórico prácticas de las áreas de estudio que fueron evolucionando en su estructura a medida que se iban aplicando; planeándolas con algunas temáticas relevantes dentro del plan de área como: un sistema de ecuaciones lineales, rectas paralelas, función cuadrática, acertijos matemáticos, el texto argumentativo, el cine foro en literatura, la historieta, la oración compuesta, el género lirico entre
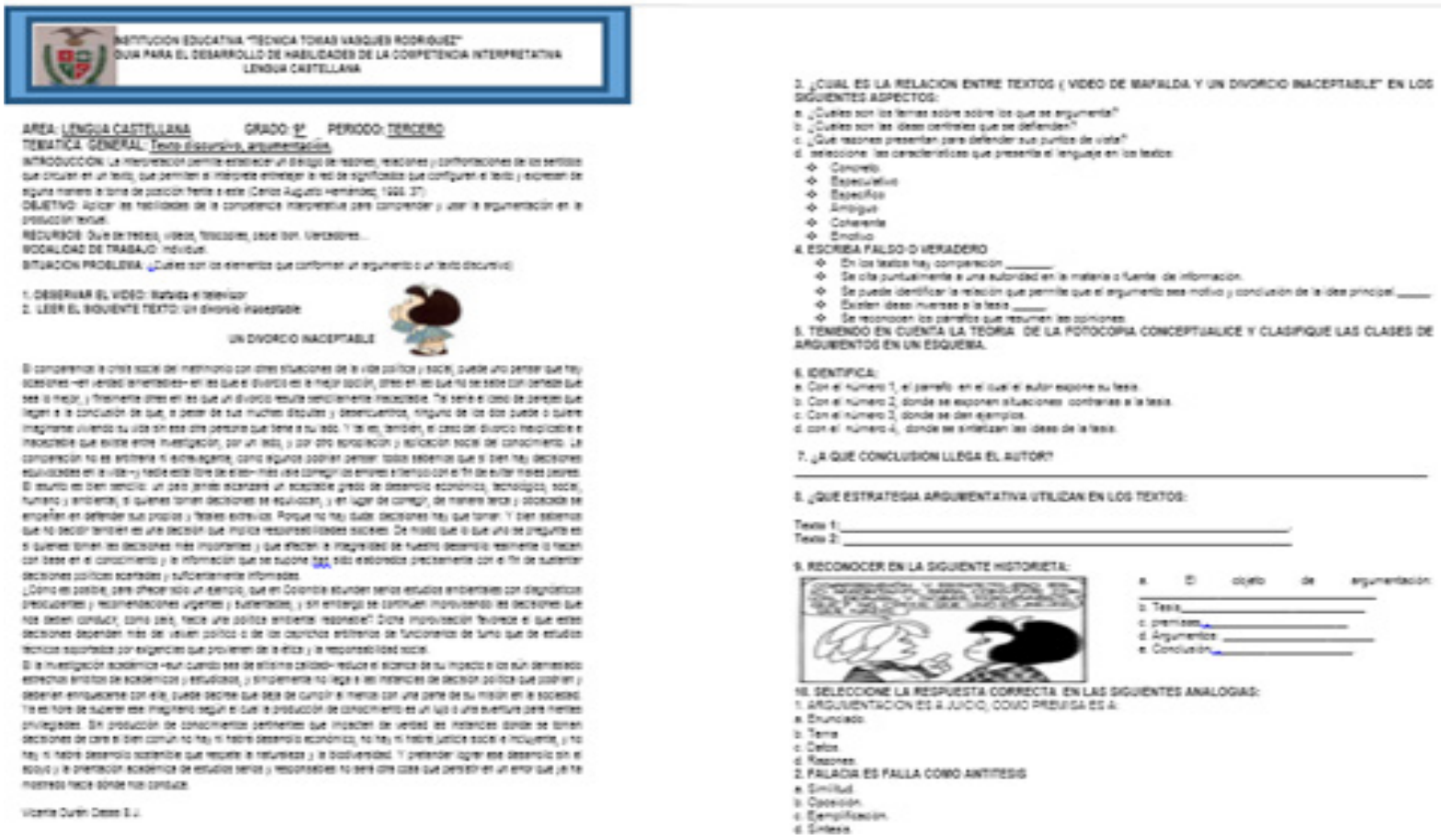


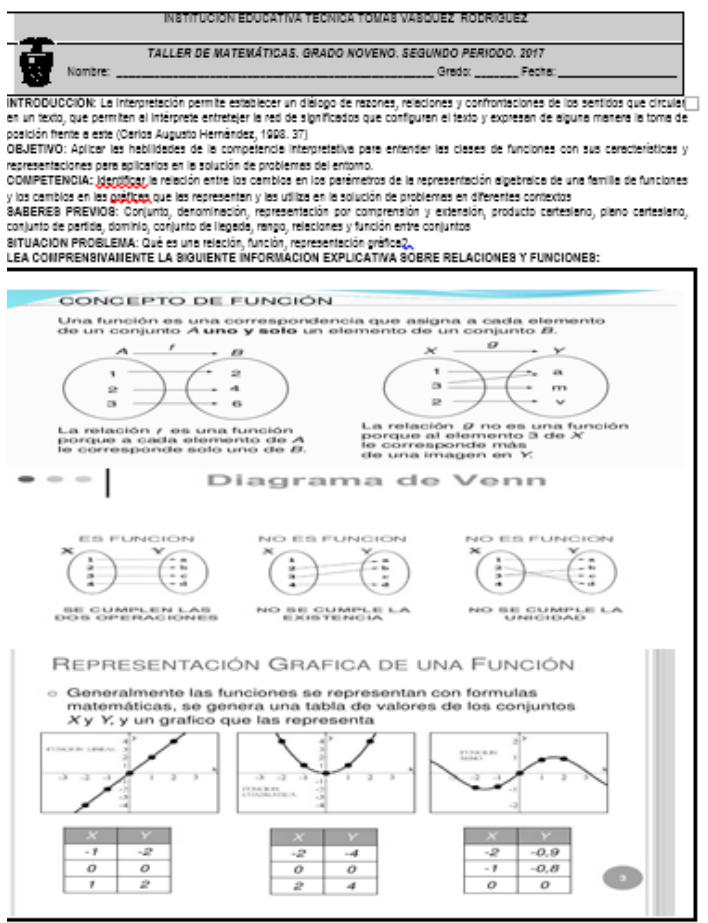

otras. Al inicio del desarrollo de las primeras guías se notó apatía por leer la información, por observar detalladamente los videos, por participar en la socialización de los mismos, por desarrollar los procesos, pero poco a poco se fue mejorando esta actitud y se notó motivación e interés para desarrollar cada una de las actividades de la tarea docente, aunque algunas veces los periodos de tiempo no era suficientes y tocaba retomarlas en las siguientes sesiones de clase.

Para la orientación y ejecución se utilizaron estrategias de aula como videos didácticos, elaboración de diapositivas, el cine foro; medios escritos como elaboración de carteleras para exposiciones, experiencias reales de los estudiantes como el uso de

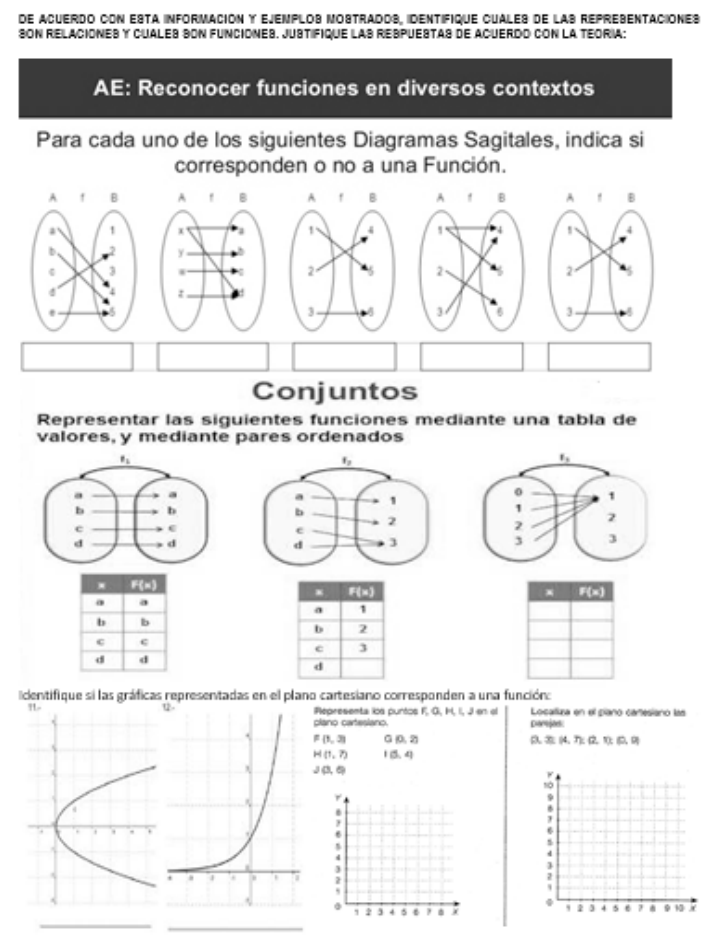

medio de transporte convencional: la bicicleta entre otras, la participación en el proyecto institucional "Hacia el desarrollo de mis competencias comunicativas" con la planeación, ejecución y socialización de guías de comprensión textual desarrolladas en el horario de dirección de grado, además se complementó con la participación activa en la emisora on line donde se trabajaron estas habilidades y como evidencia de esta tarea quedó la elaboración de una cartilla con cada una de las tareas. Además en la institución se elaboró un mural en una parte visible de la misma donde quedaron plasmadas las habilidades de la competencia interpretativa y en cada una de estas habilidades, se pegan actividades que se cambian y evalúan 


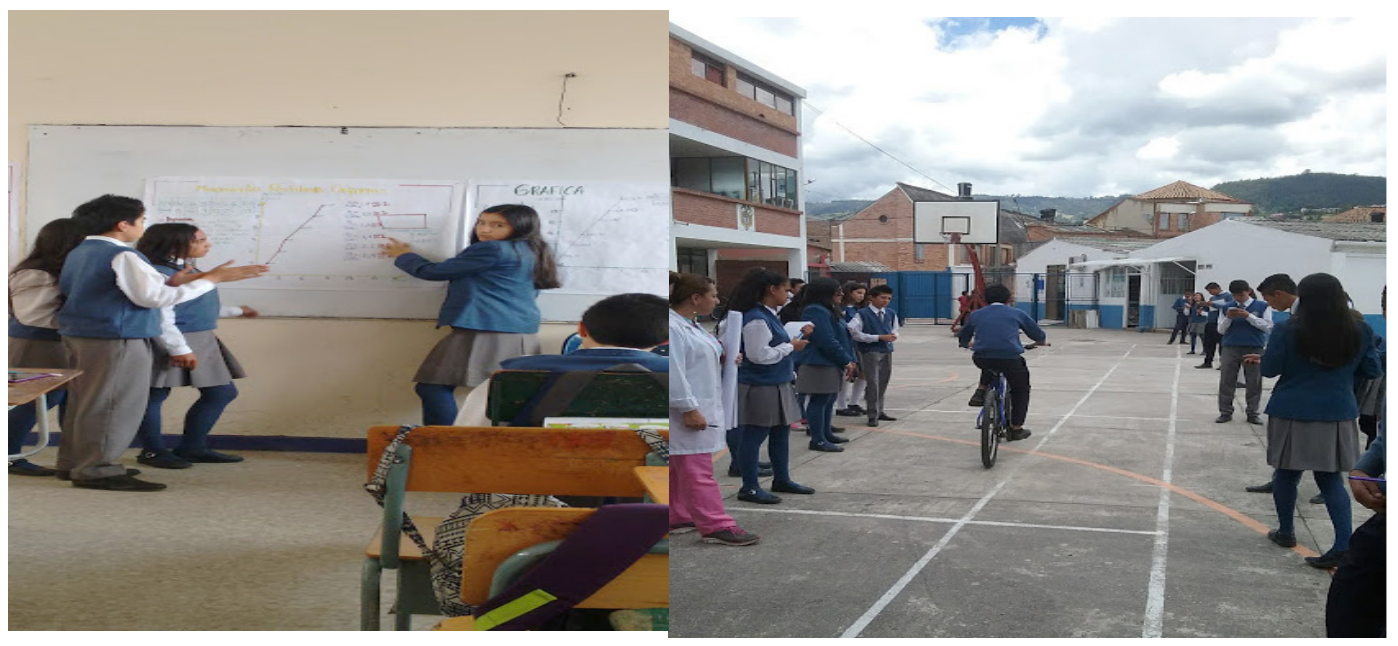

todas las semanas para lograr fortalecer procesos de aprendizaje en todas las áreas.

Para la evaluación de estas tareas docentes se utilizó una rúbrica que fue validada por la Magister en educación Gladis Estela Amézquita y en la cual está inmersa las etapas de la comprensión lectora que interviene tanto en el texto, su forma y su contenido, como los conocimientos previos que debe tener el lector y las expectativas que tiene para aprender. Esta rúbrica tuvo en cuenta el modelo ascendente en el que los educandos utilizan un modo para llegar a decodificar de manera correcta la información presente en el texto, y el descendente, porque para leer también se requiere de objetivos, conocimientos y experiencias previas, todo lo cual se encuentra mediado por la cultura. Esta teoría interactiva se sitúa ante el texto, cuando los elementos que lo componen generan en él expectativas a distintos niveles (el de las letras, las palabras...) de manera que la información que se procesa en cada uno de ellos funciona como input para el nivel siguiente; así, a través de un proceso ascendente, la información se propaga hacia niveles más elevados. (Solé, 2000).
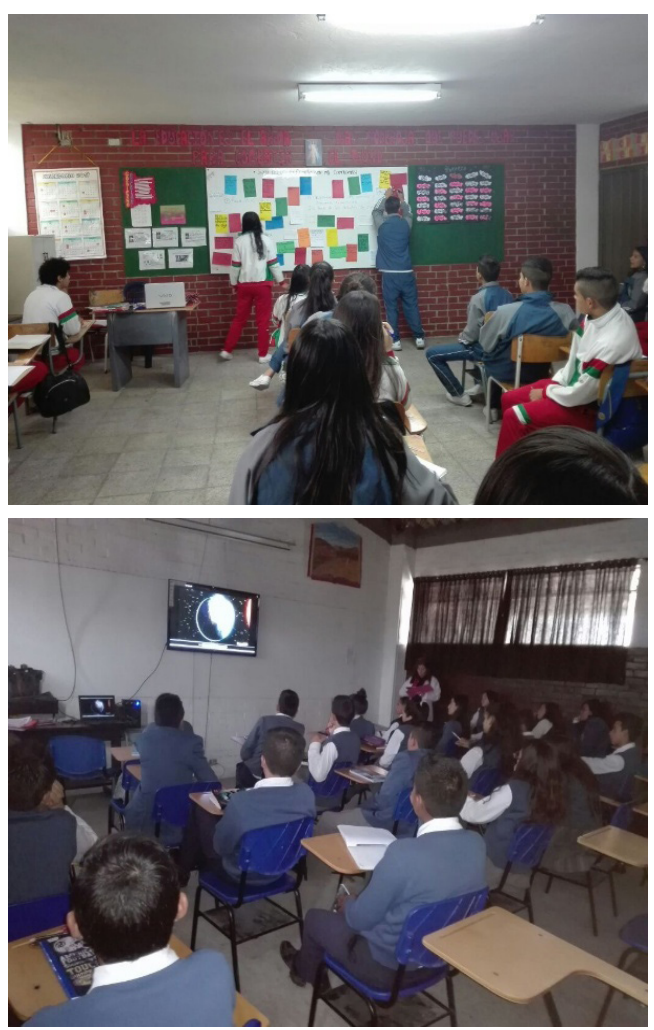


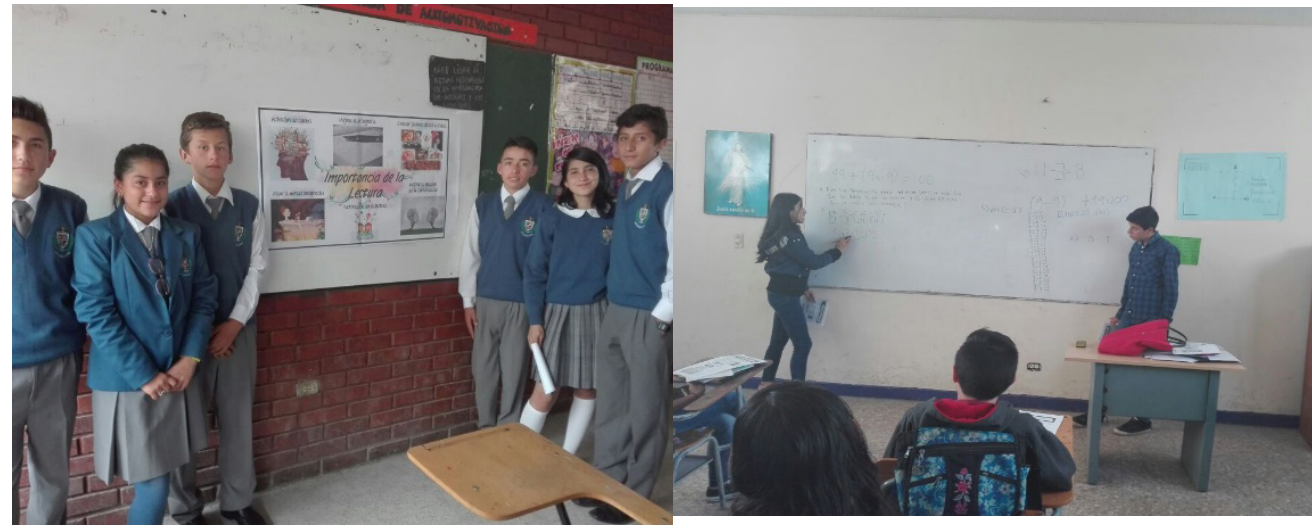

Fase 3: Análisis de resultados, reflexión, fortalecer las habilidades de la evaluación

Para analizar la información obtenida con la aplicación de la estrategia didáctica "tareas docentes" para competencia interpretativa al grupo de estudio conformado por 25 estudiantes, se establecieron las siguientes categorías y subcategorías para clasificar la información:

\section{ANÁLISIS DE RESULTADOS CATEGORIZACIÓN DE LA INFORMACIÓN}

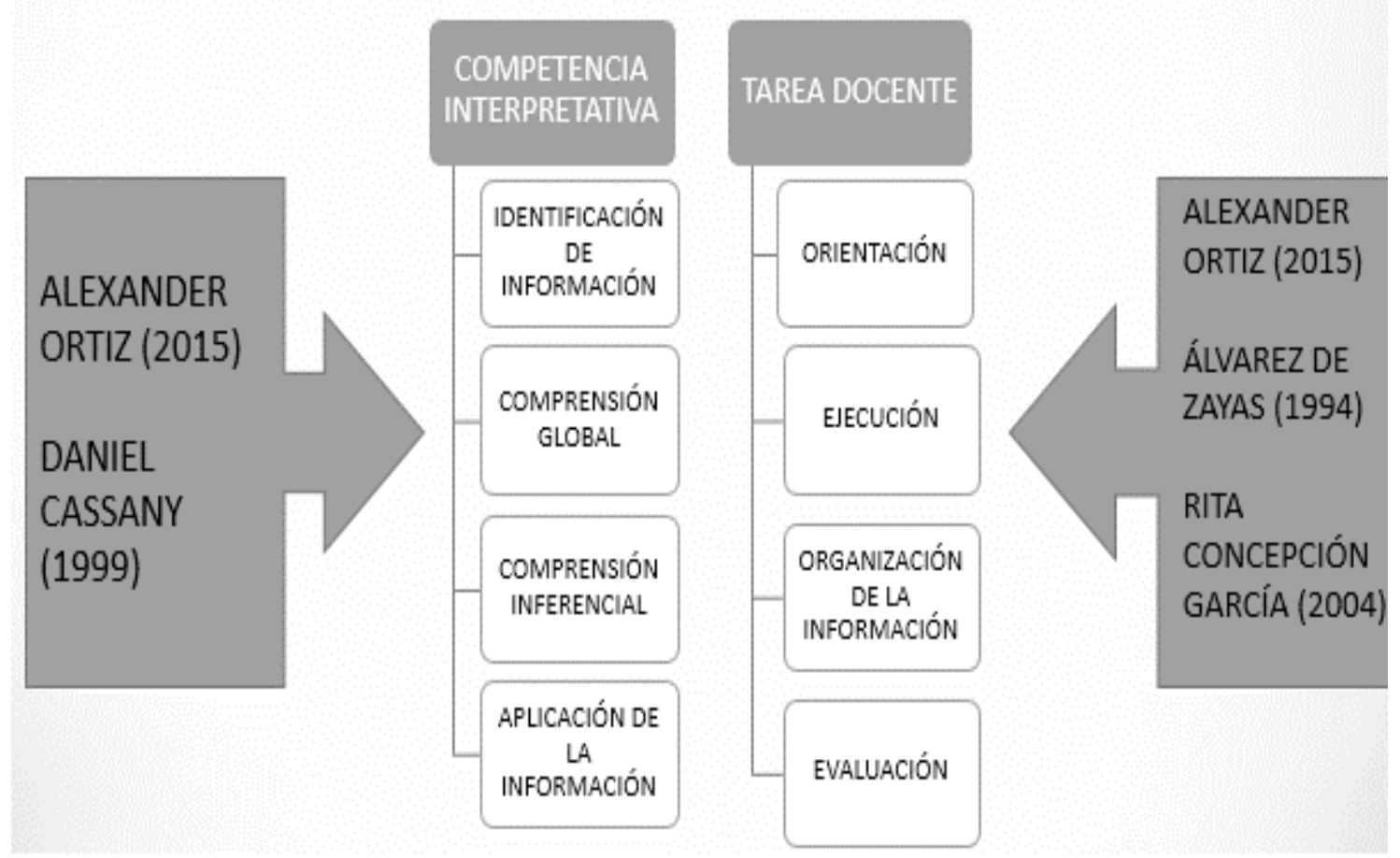




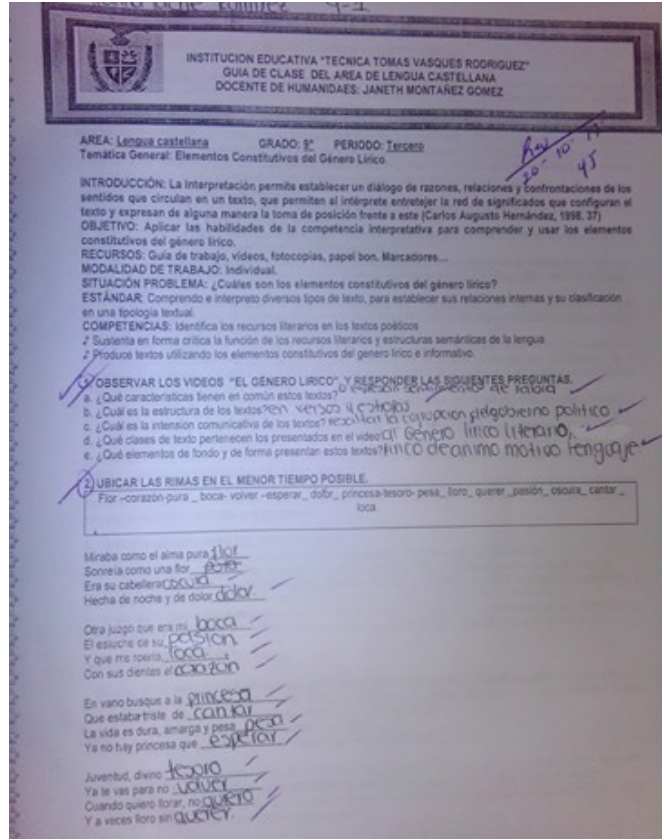

\section{Análisis de la categoría competencia interpretativa}

Para analizar la categoría competencia interpretativa se tabularon y analizaron las diez tareas docentes planeadas, diseñadas y aplicadas a los estudiantes en las áreas de matemáticas y lenguaje de acuerdo a la rúbrica de evaluación diseñada por las investigadoras, tomando como referencia los niveles de la lectura (Solé, 1994), asociando las habilidades de la competencia interpretativa (Ortiz,2015) y de acuerdo a la escala valorativa del decreto 1290 de 2009.

\begin{tabular}{|c|c|c|c|c|}
\hline \multicolumn{5}{|c|}{$\begin{array}{l}\text { INSTITUCIÓN EDUCATIVA "TÉCNICA TOMÁS VÁSQUES RODRIGUEZ" } \\
\text { RÜBRICA PARA EVALUAR LA COMPETENCIA INTERPRETATIVA. } \\
\text { MATEMÁTICAS Y LENGUA CASTELLANA. }\end{array}$} \\
\hline HABILIDADES. & \multicolumn{4}{|r|}{4 SUPERIOR } \\
\hline $\begin{array}{l}\text { IDENTIFICACION 0 } \\
\text { LOCALIZACION DE LA } \\
\text { INFORMACION } \\
\text { RELEVANTE. } \\
\text { (observar, analizar) }\end{array}$ & $\begin{array}{l}\text { Localiza escasa información } \\
\text { relevante del texto y no logra } \\
\text { establecer conexiones entre unos } \\
\text { y otros para resolver situaciones } \\
\text { problema. }\end{array}$ & $\begin{array}{l}\text { Localiza datos e información dentro del } \\
\text { texto. Pero deja del lado algunos de } \\
\text { estos en el momento de resolver } \\
\text { situaciones problema o no los toma en } \\
\text { cuenta en la reconstrucción del sentido } \\
\text { del texto. }\end{array}$ & \begin{tabular}{|l|} 
Localiza información importante del \\
texto, infiniendo significados de \\
palabras según el contexto y \\
recapitula continuamente lo leído \\
pero presenta dificultad para su \\
aplicación en la resolución de \\
situaciones.
\end{tabular} & $\begin{array}{l}\text { Localiza todas las } \\
\text { informaciones relevantes del } \\
\text { texto de acuerdo con el } \\
\text { propósito escritural y las aplica } \\
\text { en el desarrollo de las tareas } \\
\text { docentes asignadas. }\end{array}$ \\
\hline $\begin{array}{l}\text { COMPRENSIÓN } \\
\text { GLOBAL } \\
\text { (Determinar lo } \\
\text { esencial, abstraer, } \\
\text { identificar) } \\
\end{array}$ & $\begin{array}{l}\text { Le resulta dificil ubicar el tema } \\
\text { principal del texto y no reconoce la } \\
\text { función, ublidad e importancia del } \\
\text { mismo al momento de solucionar } \\
\text { situaciones. }\end{array}$ & $\begin{array}{l}\text { Ubica el tema principal del texto, pero } \\
\text { muestra dificultad para reconocer la } \\
\text { función y utilidad al momento de su } \\
\text { aplicación. }\end{array}$ & $\begin{array}{l}\text { Señala el tema principal o el } \\
\text { mensaje del texto e identifica su } \\
\text { función e importancia. }\end{array}$ & $\begin{array}{l}\text { Ubica con facilidad el tema } \\
\text { principal, su propósito y lo aplica } \\
\text { con destreza en el desarrollo de } \\
\text { la tarea docente asignada. }\end{array}$ \\
\hline $\begin{array}{c}\text { COMPRENSIÓN } \\
\text { INFERENCIAL. } \\
\text { (Comparar, describir, } \\
\text { relacionar) }\end{array}$ & $\begin{array}{l}\text { Esboza un análisis fragmentario } \\
\text { del texto a partir del acercamiento } \\
\text { sin lograr precisar que aspectos } \\
\text { puntuales lo demuestra. }\end{array}$ & $\begin{array}{l}\text { Esboza un análisis fragmentario del } \\
\text { texto a partir del acercamiento que } \\
\text { logradoe eldentifica la intensión del autor } \\
\text { a partir de algunos indicios, sin lograr } \\
\text { precisar que aspectos puntuales lo } \\
\text { demuestra. }\end{array}$ & \begin{tabular}{|c|} 
Esboza un análisis fragmentario del \\
texto a partir de las características, \\
elementos de comparación, y elige \\
los suficientes y pertinentes para el \\
desarrollo de situaciones \\
problemas.
\end{tabular} & $\begin{array}{l}\text { Esboza un análisis fragmentario } \\
\text { del texto y utiliza todas las } \\
\text { características, elementos de } \\
\text { comparación, y relación para el } \\
\text { desarrollo de situaciones } \\
\text { problemas. }\end{array}$ \\
\hline $\begin{array}{l}\text { COMPRENSIONN Y } \\
\text { APLICACIOON DE LA } \\
\text { INFORMACION. } \\
\text { (gintetizar, } \\
\text { conceptualizar, } \\
\text { caracterizar } \\
\text { interpretar) }\end{array}$ & $\begin{array}{l}\text { Hace una valoración en el texto } \\
\text { leido en el que no toma en cuenta } \\
\text { su propio saber y las } \\
\text { informaciones de otros textos } \\
\text { relacionados con el tema } \\
\text { abordado como tampoco la } \\
\text { utilidad de dicha información para } \\
\text { lograr las tareas propuestas. }\end{array}$ & $\begin{array}{l}\text { Hace una valoración en el texto pero } \\
\text { presenta dificultad para relacionar el } \\
\text { tema abordado con otros y darle } \\
\text { utilidad de dicha información para lograr } \\
\text { las tareas propuestas }\end{array}$ & $\begin{array}{l}\text { Relaciona las informaciones del } \\
\text { texto leido con los conocimientos } \\
\text { previos y los procedentes de otros } \\
\text { pero no valora la utilidad de los } \\
\text { mismos para lograr el objefivo de la } \\
\text { tarea propuesta. }\end{array}$ & $\begin{array}{l}\text { Relaciona las informaciones del } \\
\text { texto leido con los } \\
\text { conocimientos previos y los } \\
\text { procedentes de otros y valora la } \\
\text { utilidad de los mismos para } \\
\text { lograr el objetivo de la tarea } \\
\text { propuesta. }\end{array}$ \\
\hline & & & & \\
\hline
\end{tabular}




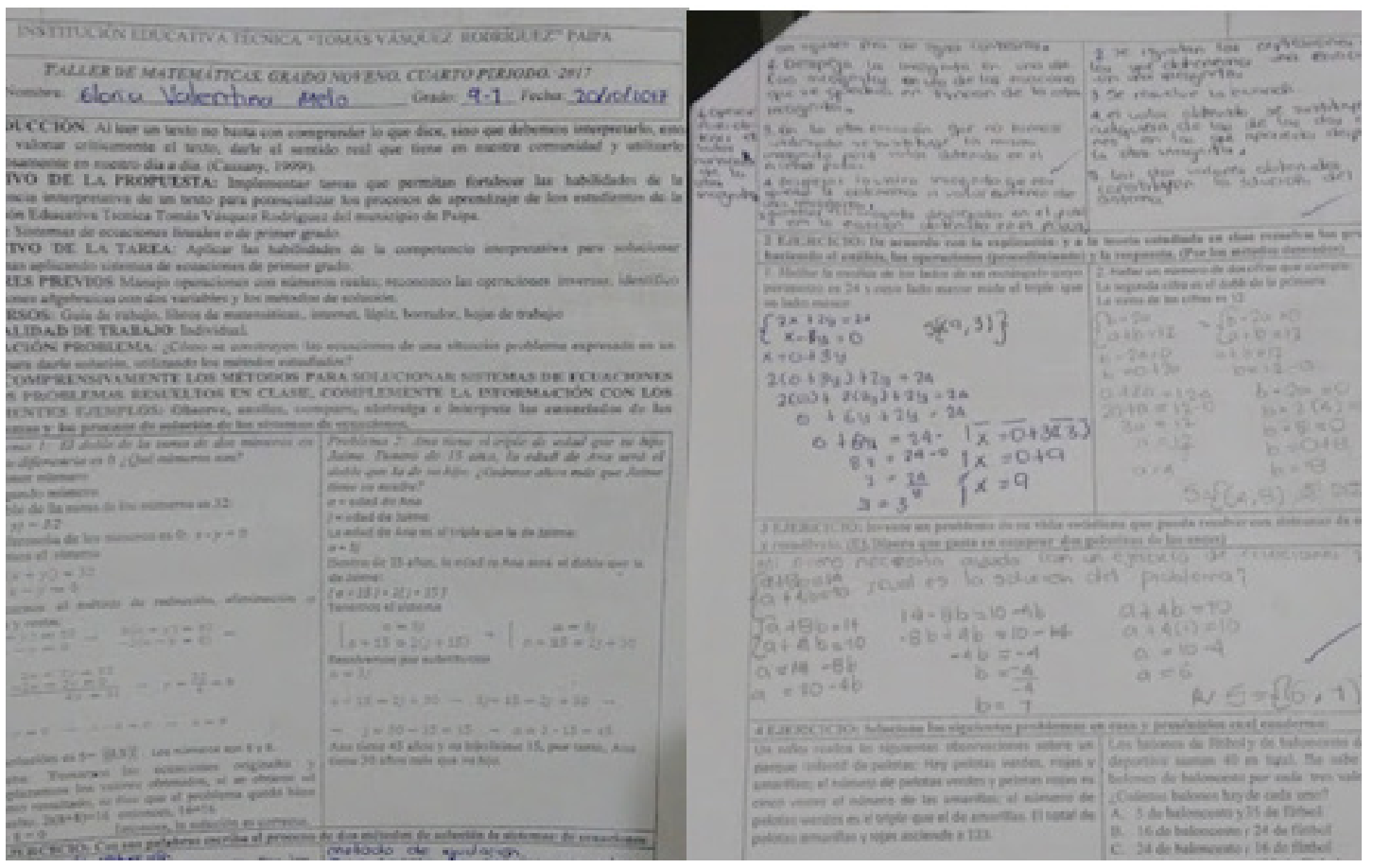

Se toma como ejemplos para el análisis las dos primeras tareas docentes aplicadas en Matemáticas y Lenguaje: Sistemas de ecuaciones lineales o de primer grado.
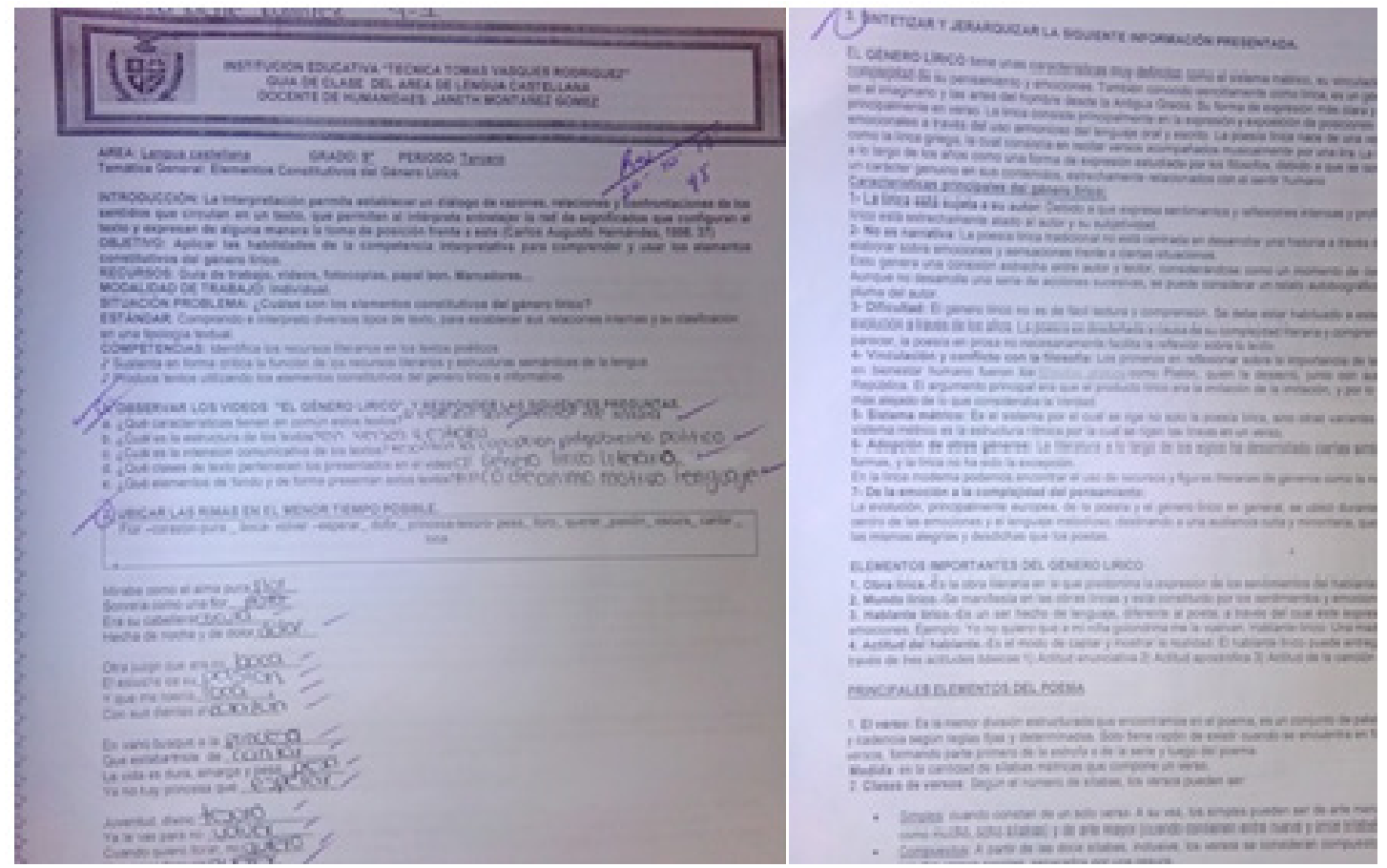


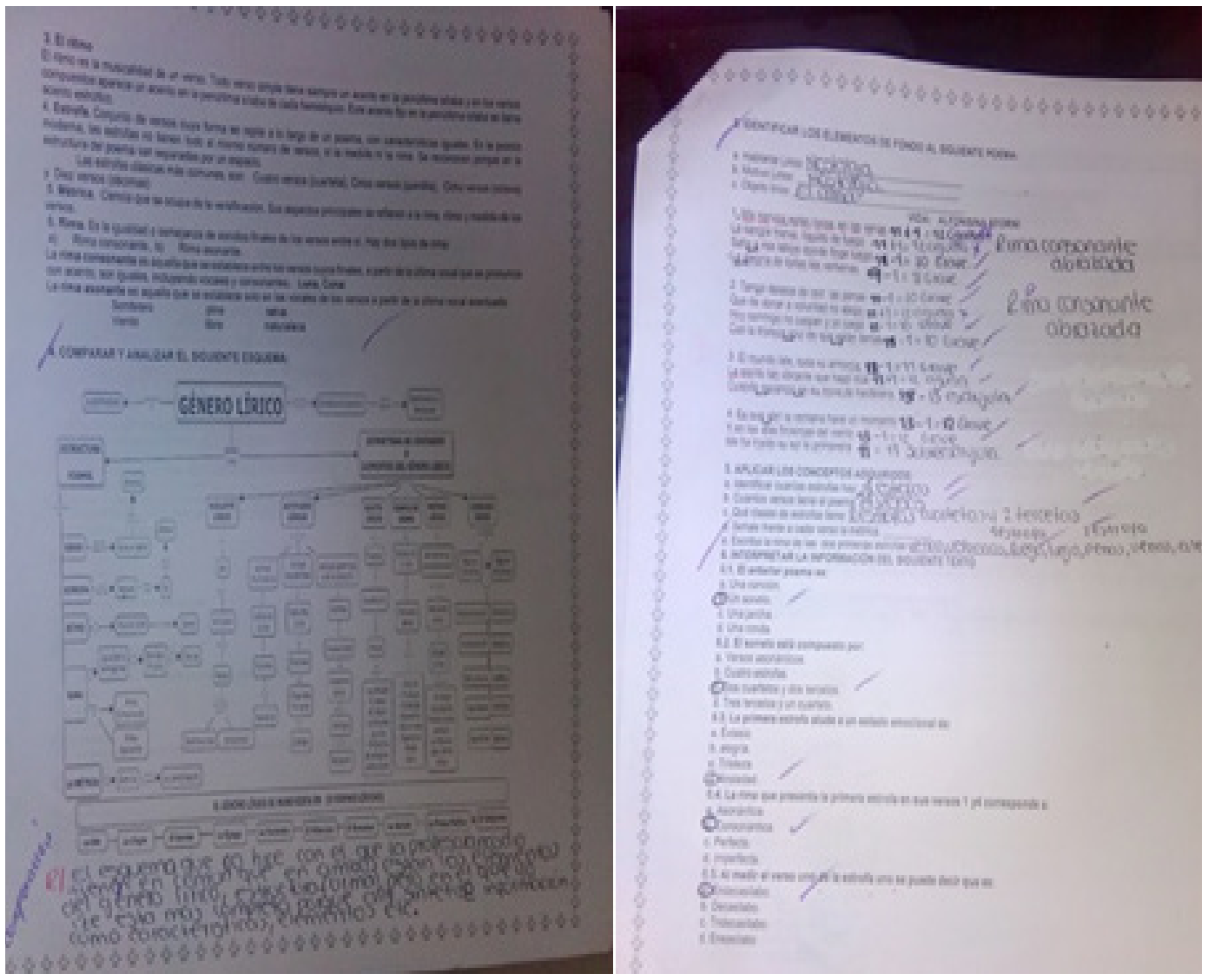

Tarea docente de Lenguaje:

Triangulando la información obtenida de las diez tareas docentes en cada una de las áreas, se obtuvieron los siguientes resultados:

Triangulando la información del desarrollo de la competencia interpretativa en las dos áreas de estudio, se obtuvo lo siguiente:

Finalmente, con estos resultados se concluye que con la implementación de la estrategia didáctica "tareas docentes", la mayoría de los estudiantes lograron los niveles superior, alto y básico $\mathrm{y}$ menos en el nivel bajo, con esto se infiere, que si se sigue trabajando esta estrategia se logrará un mejor desempeño en los niveles evaluados, mejorando los procesos de aprendizaje de los conocimientos adquiridos en su formación personal y académica.

\section{Análisis de la categoría tareas docentes}

Para analizar los resultados de la categoría tareas docentes, se analizaron los diarios de campo de cada una de las áreas de estudio, donde se plasmaron las experiencias obtenidas en el aula de clase con la aplicación de la estrategia didáctica: 
Tareas docentes de matemáticas:

- La aplicación de las tareas docentes impactó de manera positiva el aprendizaje, el comportamiento y el compromiso de los estudiantes, les crearon hábitos de puntualidad, responsabilidad y necesidad de aprender debido al reto que éstas les exigían, además, se escucharon las opiniones de otros docentes que dirigían clases en el grado, del nivel de responsabilidad, seriedad y compromiso con la que el grupo 9-1 trabajaba.

- El trabajo era personalizado y cuando tenían dudas se preguntaban entre compañeros o solicitaban explicaciones a la docente, de esta forma, comprendían con mayor facilidad porque tenían la idea de cómo iban solucionando.

- Realizaban procesos de solución muy despacio, pero bien, esto les ayudó a aprender la asignatura, además, la docente estuvo pendiente y les ayudó a resolver dudas para que ellos avanzaran.

- Tenían más cuidado con la lectura, buscaban comprenderla, preguntaban sobre los símbolos o enunciados que no entienden, buscan en el diccionario palabras desconocidas y aplican la teoría en la solución de los ejercicios propuestos, también observan y entienden los ejemplos desarrollados, analizan los gráficos y las ecuaciones para encontrar resultados, unos con mayor facilidad que otros.
- La docente durante el desarrollo de las tareas docentes aclaraba dudas para llevarlos al nuevo conocimiento, requiere mucha paciencia y trabajo porque cada estudiante tiene un ritmo de aprendizaje y aprendizajes previos, pero esto, conlleva a que el estudiante estime y valore el aprendizaje.

- Les llamó bastante la atención las guías elaboradas para la emisora de la institución, ellos opinaron que eran actividades didácticas creativas, divertidas, interesantes y agradables para desarrollar las habilidades del pensamiento y una forma agradable de aprender y reforzar las temáticas no comprendidas de matemáticas e interpretar y comprender textos e imágenes que son importantes para la solución de problemas que motivan el aprendizaje de los estudiantes, les desarrollaron el análisis, el cálculo, la agilidad mental con operaciones numéricas y la lógica.

- creó conciencia sobre la importancia de la matemática y el lenguaje, con esto, se puede concluir que con la interdisciplinaridad como en este caso con la literatura y el lenguaje se pueden desarrollar clases de matemáticas y se ponen en práctica el cálculo matemático, la lectura y la escritura, las cuáles, son muy importantes en los procesos de aprendizaje de los estudiantes para lograr un aprendizaje significativo.

- Los estudiantes hicieron un aporte constructivo a la construcción de las tareas docentes, sugirieron, animarlas, escribir menos texto y dar color, de las propuestas presentadas por los estudiantes fue escogida la siguiente: 


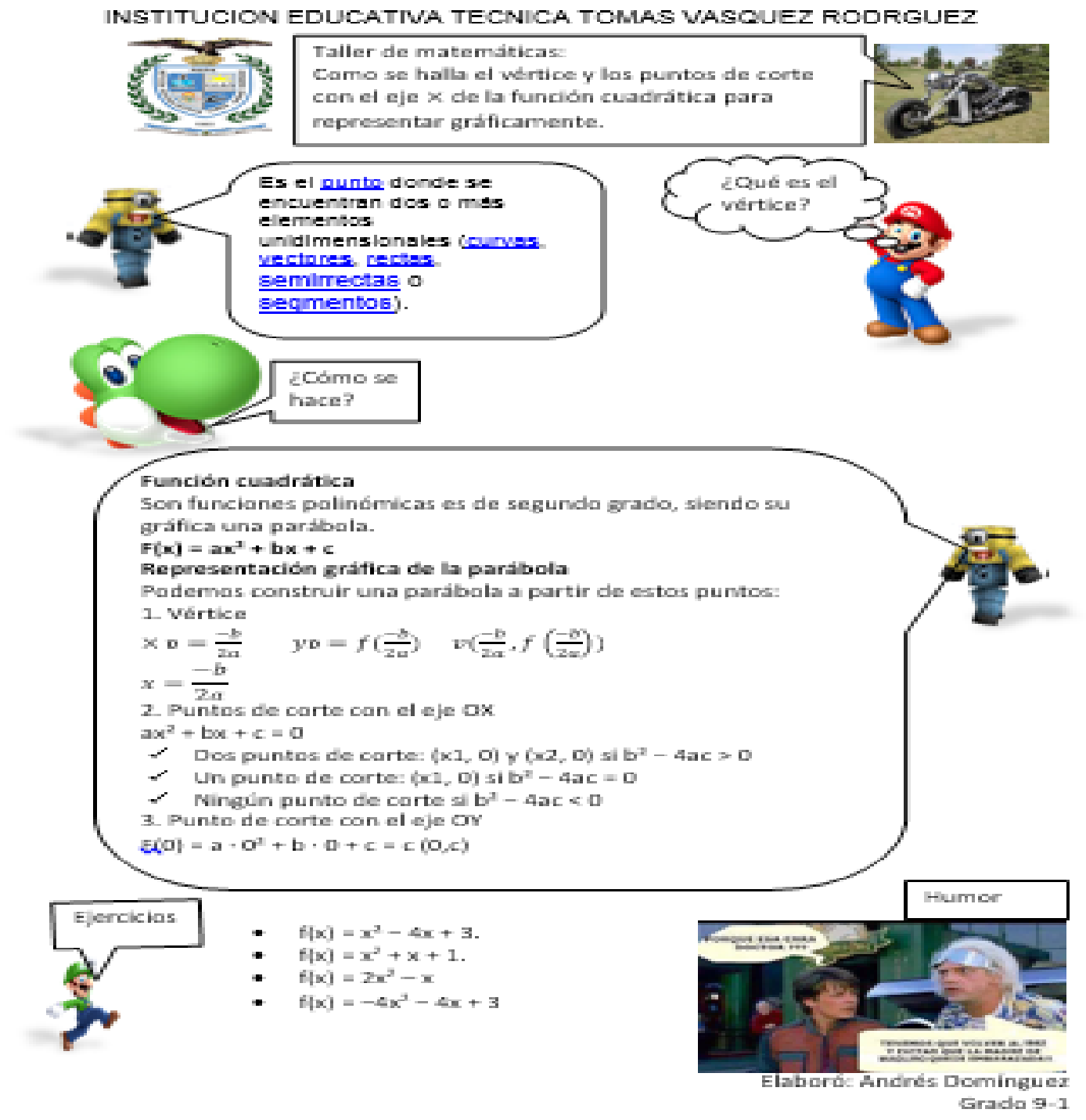

Tareas docentes de Lenguaje:

- El proceso de enseñanza el aprendizaje se particularizó ya que cada estudiante presentó diferentes dudas que fueron despejadas por la docente a través de la explicación, la retroalimentación y la socialización en el grupo, estas explicaciones del docente se dieron a través de mapas mentales, esquemas, videos explicativos, diapositivas, ejemplos, entre otros.

- El cambio de conducta y responsabilidad en el trabajo mejoró por su constante empeño en entender de manera clara y significativa los nuevos conocimientos y relacionarlos con los conocimientos previos. 
- Parala aplicación de las tareas docentes en lengua castellana se utilizaron textos continuos y discontinuos lo que permitió observar una serie de habilidades un poco diferentes a las que normalmente se usan en clase tradicional, entre estos se utilizaron textos visuales, esquemas, historietas, películas, poemas, canciones, coplas entre otros, con esta variedad se motivaba mucho mejor a los estudiantes a lograr un aprendizaje significativo y a salir de la monotonía.

- Estas tareas docentes contribuyó a ampliar estructuras sobre los temas vistos, ya que en las evaluaciones parciales mostraron mejores resultados y apropiación del mismo.

- Es importante resaltar que en la evaluación de estas tareas docentes se utilizó la coevaluación, es decir la ayuda y aportes entre compañeros; la heteroevaluación cuando el docente evaluaba el desarrollo de las tareas docentes y la autoevaluación cuando el mismo estudiante evaluaba sus procesos.

- Al realizar la evaluación final y el acta de comisión de evaluación y promoción del nivel de $9^{\circ}$ durante el año 2017 estas evidenciaron mejores resultados en el grado donde se aplicó la propuesta, ya que, el grupo de estudio tomado para la investigación solo perdieron el año dos estudiantes $\mathrm{y}$ en los otros dos novenos fueron reprobados entré 8 y 10 estudiantes.

- El aprendizaje que los estudiantes adquieren lo hacen en las aulas de la institución, porque, en casa hay escasa o no hay retroalimentación de los contenidos vistos, poca estimulación hacia la lectura comprensiva y no cumplen con las tareas de casa, por tanto, si no se logra un aprendizaje significativo en la clase olvidan rápido los conocimientos adquiridos.

Realizando la triangulación de la información obtenida de las tareas docentes en cada una de las áreas de lenguaje y matemáticas y organizándola en las subcategorías determinadas para el análisis, se concluye:

\section{Subcategorías de las tareas docentes}

\section{Orientación}

- Es de vital importancia que el estudiante tenga claro al inicio decada tarea docente el objetivo a alcanzar y que debe estar subordinado al nivel de conocimiento, motivaciones e intereses para que le permita fortalecer su aprendizaje a medida que las realice con satisfacción e interés.

- Se debe brindar explicación preliminar a los estudiantes sobre los aspectos esenciales que contiene la tarea docente, como el qué van hacer, cómo lo deben hacer, por qué y para qué, además concientizarlos de la importancia de lograr el objetivo.

\section{Ejecución}

- Con el desarrollo de estas tareas docentes se propició un aprendizaje significativo en la medida que los estudiantes asociaron sus 
conocimientos y sus experiencias con la solución de situaciones problema.

- La aplicación de un enfoque o perspectiva influye en el éxito del desarrollo de la tarea ya que permite comprender con mayor facilidad el camino a seguir para lograr un correcto desarrollo de las situaciones presentadas, ejercicios y problemas a solucionar

\section{Organización de la información}

- El tiempo dado al educando para el desarrollo de la tarea docente es clave ya que le permite analizar las orientaciones impartidas por el docente e intentar procesos de solución muy despacio, pero bien hechos.

- Siempre que el docente oriente una tarea y la controle, el estudiante está desarrollando trabajo independiente.

- El tiempo dado al educando para el desarrollo de la tarea docente es clave ya que le permite analizar las orientaciones impartidas por el docente e intentar procesos de solución muy despacio, pero bien hechos.

- Siempre que el docente oriente una tarea y la controle, el estudiante está desarrollando trabajo independiente.

\section{La evaluación}

- La evaluación de las acciones y operaciones que se realizan en cada tarea docente es sistemática ya que el estudiante individualmente tiene que exponer ante el profesor y el grupo, el trabajo realizado para la solución de las tareas propuestas.

- Al desarrollar las tareas docentes el proceso de aprendizaje se particulariza ya que cada estudiante presentó diferentes dudas que fueron despejadas por las docentes a través de la explicación, la retroalimentación y la socialización en el grupo.

- El desarrollo de las tareas docentes requiere mucha paciencia y trabajo porque cada estudiante tiene un ritmo de aprendizaje y un nivel de conocimientos previos diferente, pero esto, conlleva a que el estudiante estime y valore el aprendizaje.

Discusión de resultados:

En este proyecto de investigación partimos de un análisis de los desempeños en las pruebas internas y externas de los estudiantes y los resultados de los instrumentos aplicados en la prueba diagnóstica que cuestionaban y evaluaban los aprendizajes y competencias de la interpretación textual, donde se ponen en evidencia las falencias en las habilidades de pensamiento y del proceso lector, en concordancia con lo afirmado por Cassany (2001), es necesario incentivar la lectura interpretativa en los estudiantes para optimizar el aprendizaje significativo, porque la lectura es un proceso de construcción de significados a partir de la interacción entre el lector y el texto.

Al realizar el análisis de las categorías establecidas en la propuesta, permitió 
ver la complejidad de liderar procesos de formación en los cuales se incorporan unos niveles de lectura que van más allá de lo literal, sin tener en cuenta, el manejo integral de la disciplinas con las problemáticas del contexto educativo de los estudiantes, estos procesos de interpretación e inferencia están influenciados de elementos de significatividad, en decir, de conjeturas, de análisis de preguntas, de proposiciones, de toma de decisión, demostración de procesos, análisis inferencial y postura crítica entre otros. Ya que la formación y desarrollo de las habilidades de la competencia interpretativa están relacionadas directamente con las áreas de lenguaje y matemáticas en sus procesos de pensamiento matemático y el desarrollo de competencia comunicativa en el estudiante. De acuerdo con Ortiz, (2015), la habilidad es uno de los componentes esenciales de las competencias, que incide directamente en la efectividad del desempeño social y laboral del estudiante.

Con el desarrollo de las tareas docentes se propició un aprendizaje significativo en la medida que los estudiantes asociaron sus conocimientos previos y sus experiencias con la nueva información que se les estaba proporcionando, las investigaciones didácticas han demostrado que la estrategia didáctica de las tareas docentes es eficiente cuando el trabajo se organiza y planifica con carácter de sistema, donde, los ejercicios y los problemas son dos componentes fundamentales del objetivo didáctico de la tarea, los ejercicios constituyen un medio de repetición constante, orientada y dirigida de determinada actividad con el objetivo de asimilar conscientemente los conocimientos, habilidades y hábitos, así como su perfeccionamiento. Los problemas tienen como objetivo fundamental la aplicación de los conocimientos habilidades y hábitos en situaciones variantes. Existen diversas clasificaciones consideradas por la Dra. Rita Concepción García (2004).

Para alcanzar el desarrollo de la competencia interpretativa se requiere de un trabajo arduo de los docentes para planear, construir, guiar, asesorar, evaluar y retroalimentar el aprendizaje de los estudiantes, de manera individual, porque cada uno tiene sus propias características, motivaciones, dedicación, compromiso y pensamiento; de igual manera, por parte de los estudiantes, porque requiere de mucha responsabilidad e interés, tienen que ir actualizando los conocimientos previos, estudiar continuamente y mantener un alto grado de atención (Solé y Coll, 1990, p.163).

\section{Conclusiones}

Este proyecto de grado es el resultado de las experiencias dentro de la práctica pedagógica y de la investigación acción que se realizó en la Institución Educativa Técnica Tomás Vásquez Rodríguez y en las observaciones realizadas durante el diagnóstico que ponen en evidencia las falencias que tiene el sistema educativo con el trabajo activo de la competencia interpretativa, pues, este es uno de los objetivos de la educación, con el desarrollo de
Los problemas tienen como objetivo fundamental la aplicación de los conocimientos habilidades y hábitos en situaciones variantes. Existen diversas clasificaciones consideradas por la Dra. Rita

Concepción García (2004). 
estas habilidades se tendrán mejores procesos de aprendizaje en las áreas de lenguaje y matemáticas que permitirán establecer relaciones apropiadas de conocimiento en función de la solución de problemas y toma de decisiones con originalidad, creatividad, capacidad crítica y reflexiva.

El diseño de una estrategia didáctica permitió que se combinaran las teorías de las habilidades de la competencia interpretativa Daniel Cassany y las tareas docentes de Alexander Ortiz Ocaña, permitiendo la interdisciplinariedad entre lenguaje y matemáticas para cualificar las habilidades y los procesos de aprendizaje en estas dos áreas.
La tarea docente es una estrategia didáctica que desarrolla el trabajo independiente para fortalecer las habilidades de la competencia interpretativa en el manejo de la información entregada en un texto con el fin de asimilar el aprendizaje de conceptos para aplicarlos en la solución de ejercicios y problemas de las asignaturas y el contexto real del estudiante.

El éxito de los logros alcanzados con el desarrollo de las tareas docentes depende de la responsabilidad y compromiso de los estudiantes para mejorar sus niveles de conocimiento y del docente en la disposición para plantearlas y orientarlas.

\section{Referencias}

Ausubel, D. (1978). Psicología Educativa: Una visión cognitiva. México D.F., México: Editorial Trillas.

Blasco J. \& Pérez J. (2007): Metodología de la investigación en las ciencias de la actividad física y el deporte: "Ampliando horizontes". España: Editorial Club Universitario.

Caballo, V. (2005). Manual de evaluación y entrenamiento de las habilidades sociales. Madrid, España: Editorial Siglo XXI de España Editores.

Cassany, D. (2006). Tras las líneas sobre la lectura contemporánea. Barcelona, España: Editorial Anagrama.

Chomsky, N. (1988). El lenguaje y los problemas del conocimiento, conferencias de Managua I. Madrid, España: Editorial Visor.

Coll, C. (1993). La evaluación del aprendizaje en el currículum escolar: Una perspectiva constructivista en C. Coll y otros: El constructivismo en el aula. Barcelona, España: Editorial Graó. (Biblioteca de Aula 2) pp.163-183.

Concepción, R (2004). Material básico del curso "la clase en el modelo pedagógico integral”. Barranquilla. Colombia. 
D’Amore. (2006). Aprender la matemática para usar su lenguaje en modo universal. Nicosia, Europa (2013).

Dienes, Z. (1970). Las seis etapas del aprendizaje en matemáticas. Barcelona, España: Editorial: Teide.

Jhon E. (1990). La investigación-acción en educación. Ediciones Morata, S.L.Ministerio de Educación Nacional. (1994). Ley General de la Educación. Bogotá, Colombia.

Ortiz, L. (2015). Desarrollo del pensamiento y las competencias básicas cognitivas y comunicativas. ¿Cómo formular estándares, logros e indicadores de desempeño?. Bogotá, Colombia: Ediciones de la U.

Pérez, L., \& Rizo, C. (1998). Aprende a resolver problemas aritméticos. La Habana, Cuba: Editorial Pueblo y Educación.

Piaget, J. (1936). El nacimiento de la inteligencia del niño. Barcelona, España: Editorial Crítica.

Sánchez, C., \& Vanegas, L. (1997). Procesos de pensamiento. Una aproximación al desarrollo de la inteligencia. Tunja, Colombia: Editorial U.P.T.C.

Van Hiele, G. (1957). Structure and Insight : A theory of mathematics education. Utrecht, Holanda.

Vygotsky, L. (2001). Pensamiento y lenguaje. En: Obras escogidas, 2. ed., Tomo II (pp. 10-348). Madrid: A. Machado libros [J. Bravo, Trad., publicada en ruso en 1982]. Editorial Paidos Iberica.

Von Glasersfeld, E. (1996). Aspectos del constructivismo Radical. En M. Pakman (Editor), Construcciones de la experiencia bumana. Barcelona, España: Editorial Gedisa.

Zabala, A. (2000). La práctica educativa ¿Cómo enseñar?. Barcelona, España: Editorial Graó. 